\title{
A IMPORTÂNCIA DA NATUREZA PARA A CONSTRUÇÃO DE UMA IDENTIDADE FEMININA NA POESIA QUE TRANSPÕE O HALO, DE MARCELE AIRES: UMA ANÁLISE SOB O PONTO DE VISTA DO ECOFEMINISMO
}

\author{
Marciano Lopes Silva* \\ Universidade Estadual de Maringá
}

\begin{abstract}
Resumo: As representações da natureza variam conforme os discursos e as formas artísticas. Ao longo da história literária, elas têm sido predominantemente orientadas por interesses diversos, tais como científicos, comerciais, políticos, assim como expressivos. De um polo a outro, sua representação tem servido à divulgação de suas riquezas (como aconteceu na literatura de viagem do período colonial), à consolidação de uma identidade nacional e/ou regional (o que ocorre nas literaturas do romantismo e do modernismo, assim como do regionalismo), à afirmação das teses sobre o determinismo biológico no comportamento humano (o que ocorre na literatura do realismo/naturalismo), ou à expressão da subjetividade, seja de personagens ou de sujeitos líricos (o que ocorre especialmente na literatura românticosimbolista), orientando-se, em cada caso, por diferentes visões de mundo. Recentemente, acompanhando o surgimento de uma consciência ecológica que se contrapõe às ideologias que a consideram apenas como recurso natural a ser explorado, a natureza tem sido valorizada per si, o que não exclui sua relação com a subjetividade que a representa e para a qual ela é importante. Para discutir essa questão segundo o ponto de vista crítico do ecofeminismo, analisamos os poemas do seu livro Que transpõe o halo com o intuito de demonstrar a importância da natureza na construção de uma identidade feminina na obra em questão.
\end{abstract}

Palavras-chave: Ecocrítica. Ecofeminismo. Literatura paranaense. Natureza e subjetividade. Poesia paranaense.

\section{Introdução}

As representações da natureza variam conforme os discursos e as formas artísticas. Ao longo da história literária, elas têm sido predominantemente orientadas por interesses diversos, tais como científicos, comerciais, políticos, assim como expressivos. De um pólo a

\section{(9) $\circledast \Theta$}

\footnotetext{
* Possui graduação em Oceanologia (1988) e Letras (1991) pela Universidade Federal de Rio Grande, mestrado em Letras pela Universidade Federal do Rio Grande do Sul (1994) e doutorado em Letras pela Universidade Estadual Paulista Júlio de Mesquita Filho (2005). É professor adjunto D da Universidade Estadual de Maringá.
} 
outro, sua representação tem servido à divulgação de suas riquezas (como aconteceu na literatura de viagem do período colonial), à consolidação de uma identidade nacional e/ou regional (o que ocorre nas literaturas do romantismo e do modernismo, assim como do regionalismo), à discussão sobre o determinismo biológico no comportamento humano (o que ocorre na literatura do realismo/naturalismo), ou à expressão da subjetividade (o que ocorre especialmente na literatura romântico-simbolista), orientando-se, em cada caso, por diferentes visões de mundo. Recentemente, acompanhando o surgimento de uma consciência ecológica que se contrapõe às ideologias que a consideram apenas como recurso natural a ser explorado, a natureza tem sido valorizada per si, o que não exclui sua relação com a subjetividade que a representa e para a qual ela é importante. Isso é o que acontece em todos os textos do primeiro livro de poemas de Marcele Aires: Que transpõe o halo. Nele, o louvor à natureza está intimamente associado à construção e afirmação de uma identidade feminina profundamente telúrica. Nos poemas, a autora recusa o gozo racionalista ocidental e como boa filha de Ogum mergulha nas matas e nas águas, põe os pés descalços no chão e os antúrios na cabeça e sai em busca de uma relação sensual e sensorial com a natureza, liberta dos grilhões da moralidade castradora. E esta associação entre natureza e afirmação de uma identidade feminina leva inevitavelmente o olhar crítico à reflexão sobre a existência do ecofeminismo em sua poesia.

Para o ecofeminismo clássico espiritualista assim como para o ecofeminismo cultural, a natureza é um elemento importante na construção da subjetividade feminina na medida em que existe uma identificação entre mulher e natureza, posto que a primeira, assim como a segunda, são geradoras de vida. Para ambas correntes citadas, há uma valorização da espiritualidade e do misticismo em oposição às religiosidades cristã, judaica e islâmica na medida em que elas, sendo expressivas da ordem patriarcal, perseguiram todas as religiões e cultos matriarcais, condenando-os como pagãos, demoníacos e irracionais, assim como perseguiram as antigas divindades femininas e as mulheres que detinham conhecimentos mágicos. A identificação da mulher à natureza, considerado-a como irracional, perigosa e inferior, constitui o par antitético da identificação do homem à cultura e à civilização. Esta crítica ao patriarcalismo, que também encontramos no ecofeminismo de Vanda Shiva e Maria Mies (1993), representantes mais conhecidas do ecofeminismo do Terceiro Mundo (ou do Vento Sul), é fundamental para o ecofeminismo, especialmente por ser um dos poucos pontos teóricos compartilhados entre suas diversas correntes. Sobre estes dualismos e outros que têm 
sustentado a dominação masculina ao longo da história de nossa civilização ocidental, escreve Regina Di Ciommo:

\begin{abstract}
Diferentemente do feminismo social, que discute a igualdade de mulheres e homens sem questionar sistemas fundamentais de valores, o Ecofeminismo mostra como a cultura ocidental tem progressivamente desenvolvido um sistema desigual e tendencioso que valoriza os homens acima das mulheres, a cultura acima da natureza e a mente acima do corpo. Tal sistema se expressa de mil maneiras diferentes por toda a história ocidental, desde a perda da cultura das deusas da Velha Europa até a ascensão da religião patriarcal, da decadência da magia à ascensão da ciência, a exaltação da mente e da razão e a desvalorização de nossos corpos físicos, especialmente a experiência corporal das mulheres; da colonização das terras estrangeiras e povos nativos pelos brancos europeus para as atitudes atuais mais comuns com ração ao meio ambiente (DI CIOMMO, 1999, p. 185).
\end{abstract}

Em comum aos ecofeminismos clássico, cultural e/ou espiritualista, terceiro mundista e radical (cf. DI CIOMMO, 1999; GARCIA, 2009; GUERRERO, 2010; PULEO, 2008), encontramos o afã de reencantar o mundo, uma vez que o racionalismo científico, que considera a natureza como objeto a ser explorado em prol do progresso tecnológico e econômico, é considerado como um dos principais aspectos da cultura patriarcal responsáveis pela inferiorização da natureza e das mulheres, assim como da da opressão sobre ambas. Segundo esta perspectiva claramente sintonizada com uma visão de mundo romântica - na medida em que constitui uma crítica ao capitalismo, reivindica o reencantamento do mundo e busca a recuperação de uma suposta integridade cósmica perdida em um distante passado comunal (LÖWY, SAYRE, 1995) - é necessário que o ser humano passe a respeitar e cuidar da natureza para que possa realmente protagonizar uma profunda e verdadeira mudança em seus valores, o que implica especialmente em mudar a maneira como concebe e se relaciona com ela. Em outras palavras: sem uma identificação profunda com a natureza, o que somente é possível na medida caso seja considerada sagrada e passe a ser um elemento positivo na constituição da subjetividade e da espiritualidade, não será possível uma mudança radical na forma do ser humano se relacionar com a natureza e o meio ambiente. Por isso é necessário reencantá-la através da invenção e/ou do resgate de antigos mitos e ritos esquecidos ou silenciados pelo patriarcalismo, conforme demonstra Edward Whitmont (1991).

É importante ressaltar que a escolha desta obra não significa que ela tenha necessariamente uma orientação ecológica, ou seja, uma temática voltada à preservação do meio ambiente e à denuncia de sua exploração. É certo que devemos levar em conta a advertência quanto ao fato de "que os critérios ecocríticos tendem a parecer amplos demais, incorporando uma vasta gama de obras literárias em que figura a 'natureza', ou estreitos demais, excluindo o que não constitui uma obra de clara orientação ecológica" (Buell apud 
Garrard, 2006, p. 81). No entanto, considerar que a obra deva apresentar uma preocupação com o meio ambiente não humano para sua eleição pelo crítico nos parece um critério por demais estreito, pois obras que não tenham esta orientação podem ser muito úteis e produtivas para uma reflexão sobre as maneiras como o homem interage com o meio ambiente natural, de modo que nos parece muito mais acertada a posição de Mauricio Ostria González:

La perspectiva ecocrítica, claro, no debe limitarse al análisis obvio de textos que evidencian sin más una temática enraizada en la valoración de la naturaleza; tampoco en la descalificación o censura sin más de textos de diversa catadura que excluyan las preocupaciones por el medioambiente. Me parece, en cambio, más razonable y productivo, abordar, desde un enfoque ecocrítico, cualesquiera prácticas textuales, buscando indagar en ellas, la presencia (explícita o implícita) de la naturaleza, en tanto sujeto-objeto en constante dinamismo, y del ser humano en interacción (positiva o negativa) con ella. (GONZÁLEZ, 2010, p. 107)

Assim considerando, orientamos a análise e discussão que seguem com base nas seguintes questões:
a) Existe uma preocupação ambiental em sua poesia?
b) Qual o papel/a função da natureza em sua poética?
c) Que relações são estabelecidas entre natureza e feminilidade?
d) Há uma postura ecofeminista em seus poemas?

\section{Natureza e espiritualidade: cabeça nas nuvens e pés encardidos}

Seu primeiro livro, Que transpõe o halo, foi publicado em 2010 e é composto de uma trilogia poética: "Antúrio nos cabelos, pés encardidos", "Aérea essência" e "Minérios forjados" - subtítulos que já apontam para uma forte relação do sujeito lírico com a natureza.

A constante recorrência da imagem dos "pés encardidos" traduz a profunda relação entre o sujeito lírico feminino e a terra, pois os pés sujos de terra simbolizam a atitude pouco urbana de andar de pés descalços, mantendo-se em contato direto com a terra, trocando energia com a natureza sem mediações culturais. Ao mesmo tempo, estar descalço simboliza tanto a simplicidade quanto a humildade, o despojamento de qualquer proteção e símbolo de status e/ou poder.

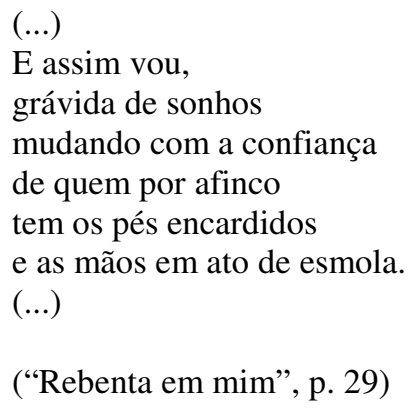

(“Rebenta em mim”, p. 29) 


\section{$(\ldots)$}

O corpo é o começo da travessia.

Como é preciso molhar os pés!

Tanta sujeira estancada nas unhas ainda

até que a ceifa esteja pronta!

(...)

(“O enigma sustenido", p. 32)

O desejo de estar em meio à natureza, ser natureza, ou simplesmente deixar que ela se manifeste em nosso ser, perpassa cada verso do livro e transborda em signos que nos remetem para longe do mundo urbano rumo a uma integridade cósmica. Um poema que sintetiza muito bem esta atitude do sujeito lírico é "Telúrica”, o qual recupera diferentes mitos em que a mulher é criada da terra e/ou da natureza, como é o caso do mito de Lilith, que foi criada do barro, ou de um mito celta, citado por Regina Di Ciommo (1999, p. 169), em que ela é composta pelos elementos da natureza: "Seu corpo foi feito com barro da terra, (...). Seus ossos e dentes foram feitos com as conchas das criaturas do mar e os minerais das rochas. Seu cabelo foi feito de hera e grama. A luz dos seus olhos (...) era a luz do sol, da lua, das estrelas".

Fértil angústia.

De minha terra germinam

insetos de polida casca,

caramujos de notáveis broqueis,

multifacetadas centopeias,

orgânicas formigas,

indecifráveis aranhas.

De meu ventre espocam

plantas de um verde venusto,

frutígeras árvores,

alígeros pólens,

selvas de odor pungente,

grossos tubérculos - tão duros, másculos,

absurdamente obscenos.

O meu cheiro de fêmea

se sabe em úmido solo,

mata ciliar que se fecha em pêlos,

arbustos, territórios de romãs,

roçar das correntezas

em pedra de dura luz.

Eu agora apanho a mudez do dia.

Ruído só de água;

voz cromada no rústico,

na inacabada carne

que insiste em selar

o refluxo do incognoscível. 


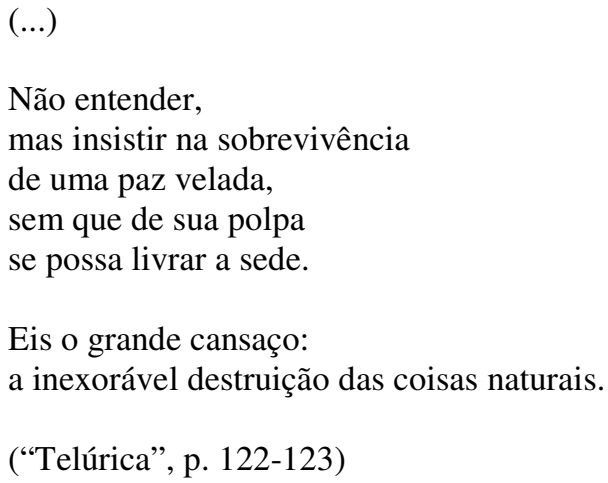

No poema acima, é difícil saber se o sujeito lírico dá voz a terra ou é a voz de uma mulher que a ela se compara. Provavelmente o que temos são as duas possibilidades imbricadas, na medida em que o sujeito lírico feminino se identifica com a Terra, planeta cuja carne é a terra de onde germina a vida em suas infinitas formas e insolúveis mistérios.

Este desejo de re-ligação com a natureza fundamenta (não esqueçamos que a palavra religião tem origem no vocábulo latino religare, significando religação com o divino) a forte religiosidade que perpassa a sua obra e que não se restringe a uma religião, embora exista uma clara preferência pela religiosidade afro-brasileira, revelada nas saudações e referências a Orixás, destacando-se Iemanjá (“Arrastão”, p. 145-146) e Ogum, o Orixá ferreiro ou senhor dos metais, quem forja as ferramentas para a caça, agricultura e guerra. Orixá que tem sua contrapartida católica na figura de São Jorge Guerreiro, para quem a autora faz o poema “Oração a Jorge" (p. 124). Porém, mais importante do que um credo religioso específico, é a fé. Toda fé que não elida a natureza, mas, diversamente, ponha o homem novamente em comunhão com ela, que lhe possibilite religar-se material e espiritualmente ao cosmos. Esta abertura para outros credos ou filosofias também está presente nas fotografias do ensaio de Graziela Diez sobre butaneses. 


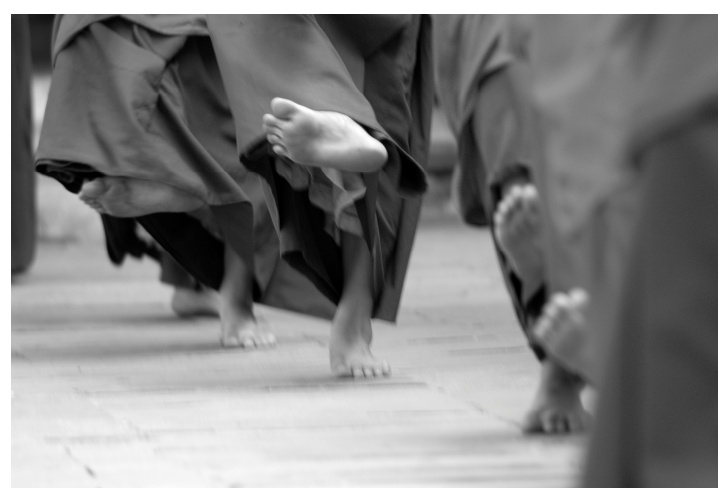

Fig. 1: Terra em transe III Fotógrafa: Graziela Diez

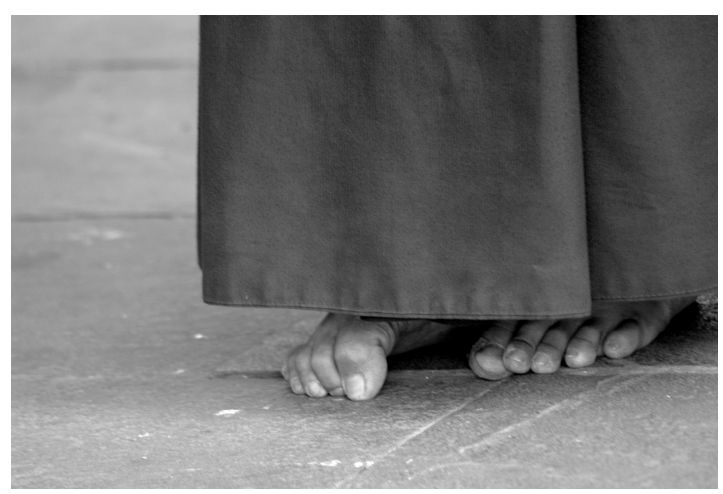

Fig. 2: Terra em transe V

Fotógrafa: Graziela Diez

Entre as fotos de Graziela Diez que acompanham os poemas de Marcele Aires, são várias que destacam os pés descalços de monges zen-budistas (p. 22, 24, 53 e 57). Ao incluílas em seu livro, a autora estabelece um diálogo entre elas e sua poesia e sugere que a filosofia zen-budista (religião oficial do Butão) também lhe orienta o caminhar:

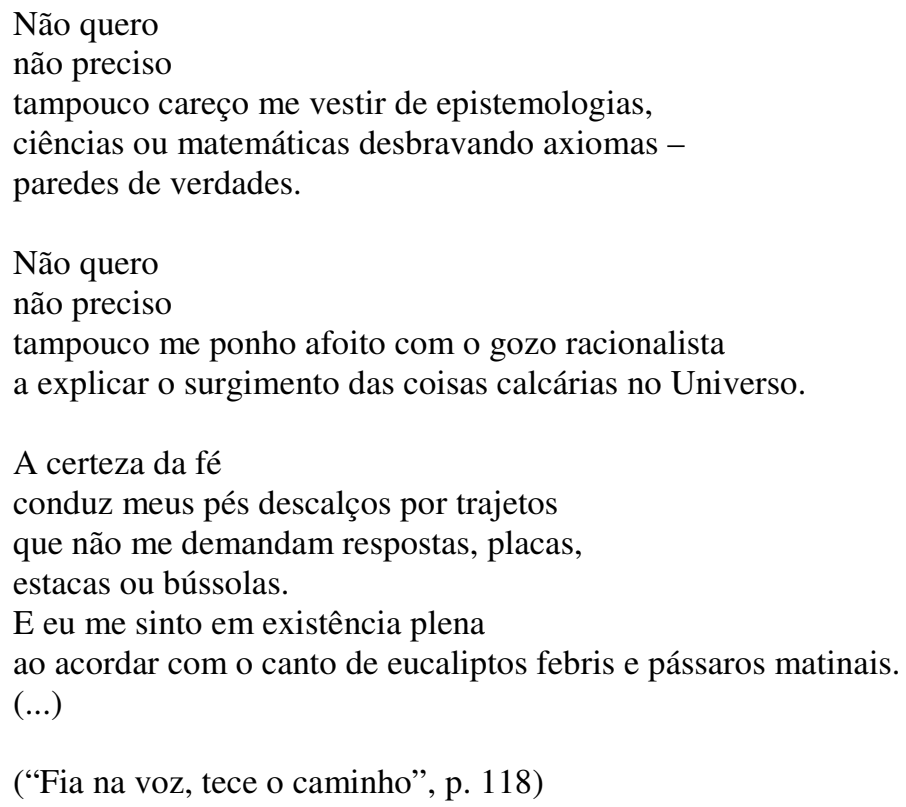

("Fia na voz, tece o caminho", p. 118) 
(...)

Os pés,

ah! Os bonitos pés!

Aqueles pés danados!

Pés vitais como os de Pedro pescador,

imaculados como os de Buda a percorrer mil caminhos,

as solas cortadas,

os dedos desgrenhados,

a sujeira bendita por entre as unhas.

(...)

(“Arrastão", p. 145)

O sujeito lírico renega o "gozo racionalista" característico de nossa maneira ocidental de pensar em troca de uma percepção intuitiva e imagética do mundo, atitude característica da sensibilidade oriental e, no caso, do zen-budismo, cujo caminho proposto para se alcançar a iluminação, ou satori, não passa pelo pensamento racional.

O treinamento nas comunidades zen encaminha as consciências em direção a um despertar ("satori", em japonês), uma iluminação, indescritível, intransferível. O desabrochar de uma consciência icônica, talvez. (LEMINSKI, 1990, p. 115).

Esta dimensão filosófica e mística que observamos esclarece a importância do segundo subtítulo do livro: "Aérea essência". Apesar de visceralmente telúrica, sua poesia almeja a transcendência rumo a uma elevada espiritualidade.

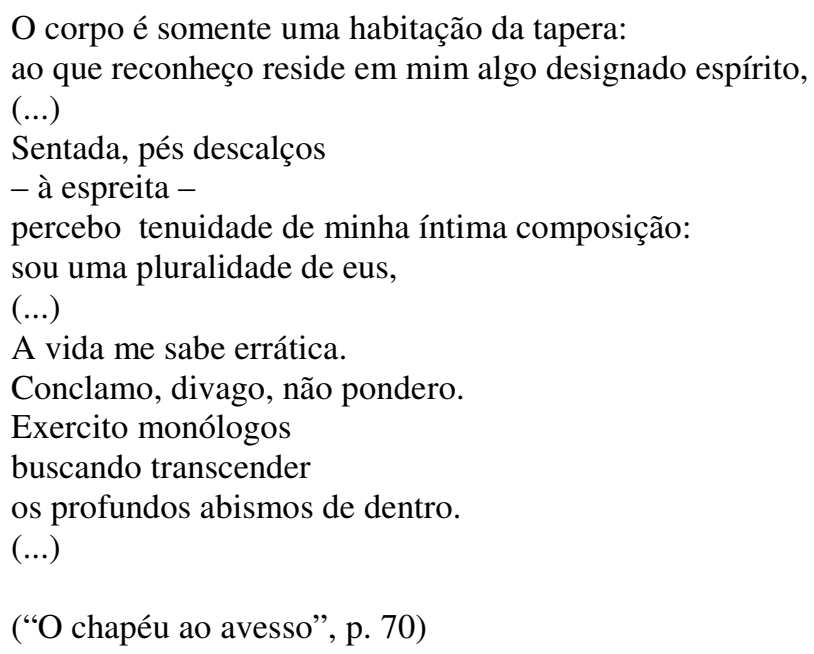

Outra imagem que merece consideração no primeiro subtítulo é a do "antúrio nos cabelos". Esta imagem, diversamente daquela dos pés descalços encardidos, não é recorrente, porém é muito significativa na medida em que traduz simbolicamente a dimensão erótica de sua poesia e da identidade feminina por ela construída.

O antúrio, originário da América do Sul, é uma folhagem muito ornamental, com folhas grandes e verdes. Suas inflorescências são espigas, protegidas por folhas modificadas 
de cores diversas (vermelha, rosa ou branca) em formato de coração. $\mathrm{O}$ antúrio vermelho com a inflorescência amarela tem imageticamente um apelo erótico ainda mais forte do que as de outras cores porque o vermelho intenso (de vinho tinto ou sangue) da folha modificada faz com que ela também pareça uma vulva aberta e destaca por contraste a espiga amarela, que lembra, em seu formato, o órgão sexual masculino. Baseado em tais analogias, parece-me plausível interpretar que a referência à presença do antúrio na cabeça possa ser interpretada como metáfora para uma sensibilidade extremamente erótica, plena de sensualidade. Tal interpretação também encontra respaldo no "telurismo" do sujeito lírico feminino e sua atitude de valorizar muito mais a fé, a experiência sensorial e a vivência ingênua do momento do que a razão, encontrando a plenitude no deleite da natureza. Daí que seus poemas sejam exuberantes, de fôlego, com versos livres carregados de imagens que jorram como águas de rios caudalosos ou despencam como águas de cachoeira - pois quase invariavelmente são longos e carregados de enumerações.

A essência desta poética plena de sensualidade, que não se deixa conter pela forma, em princípio não parece ser bem traduzida pela metáfora "Minérios forjados", subtítulo que abre a terceira parte do livro. Diversamente da poesia de João Cabral de Melo Neto que a autora admira e homenageia no poema "II) O fazedor de pedras" (p. 38), segundo da "Trilogia Oropa-Recife-Pernambucália” (p. 35), a poesia de Marcele Aires não é cerebral, planificada como projeto de engenheiro ou arquiteto, dura como a pedra do sertão nordestino. Muito diversamente, sua poesia é água corrente, ou melhor, lava corrente, pois ardente, sensual, cheia de desejo de vida que explode a cada imagem. E quando pensamos deste modo, considerando-a como lava e não água, ilumina-se o sentido da expressão "minérios forjados" como mais uma imagem definidora da sua poética. Lembremos que a lava vulcânica é material geológico em fusão, ou seja, é composta por rochas em estado líquido. Em outras palavras, é minério fundido pelo calor que faz nas entranhas da Terra. Pensando assim, a metáfora torna-se realmente ótima, pois sugere que seus poemas são como minérios forjados, resultantes dos minerais que habitam as entranhas do planeta, os quais são derretidos por seu calor de fêmea para depois serem forjados em formas poéticas pelo trabalho de arte:

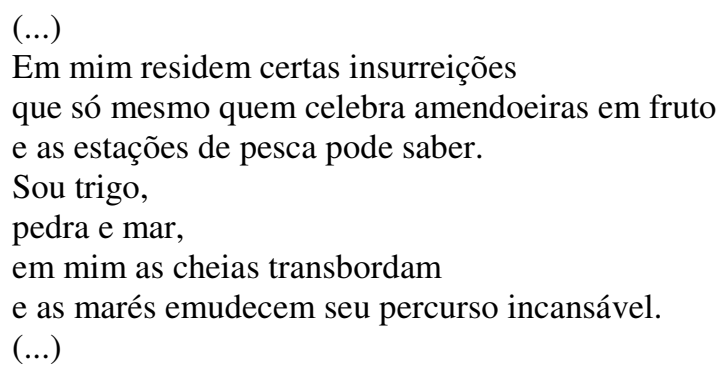


Como se vê, a poesia de Marcele Aires forja uma identidade feminina marcadamente telúrica, que se confunde e se identifica com a mãe-terra em sua condição selvagem, pois aparentemente não encontramos nela imagens de uma natureza domesticada, de jardineiro, agricultor ou turista. Em outras palavras, o motivo do locus amoenus, tão comum na poesia de tradição romântica ou bucólica, está praticamente ausente. Esta dimensão telúrica, em que o corpo feminino é marcado por signos da metamorfose e da fecundidade da terra mesclados a outros que expressam sua sensualidade, parece apontar para uma identidade feminina construída sob o arquétipo de Afrodite (que é citada no poema "Afrodite quer falar", p. 97) e/ou, mais especialmente, o de Lilith. A favor da segunda identificação arquetípica, temos a metáfora dos minérios forjados para seus poemas. Conforme argumentamos anteriormente, a imagem dos minérios forjados nos leva à imagem de minérios oriundos de lavas vulcânicas e, no imaginário ocidental, as lavas vulcânicas - assim como Lilith - estão associadas ao demoníaco, seja devido as suas elevadíssimas temperaturas, seja devido às suas emissões gasosas, que tem no dióxido de enxofre $\left(\mathrm{SO}_{2}\right)$ um dos seus principais elementos. O enxofre, elemento químico cujo odor está associado ao inferno e ao demoníaco, está presente até mesmo nas erupções - chamadas de ressurgências - que ocorrem nas profundezas abissais dos oceanos, nos pontos de consumo ou produção de placas tectônicas onde se "criam saídas, fontes de águas sulfurosas quentes e infiltrações [que] sustentam comunidades únicas (...) diferentes de qualquer coisa já descoberta no oceano" (ODUM; BARRET, 2007, p. 418), pois ricas em sulfato de hidrogênio $\left(\mathrm{H}_{2} \mathrm{~S}\right)$. Porém é arriscado definir um arquétipo básico, posto que o eu-lírico deixa claro que é composto por "uma pluralidade de eus" ("O chapéu a avesso", p. 70). O certo é que ele tem a independência e a rebeldia de Lilith e está disposto a falar o que pensa e viver de forma livre, pois como afirma no poema "A Zabé disse que o sol raiou": "Mulher de verdade conserva a sola do pé suja / e o halo limpo" (p. 76).

\section{Ecofeminismo cultural e romantismo}

Não encontramos na poesia de Marcele Aires uma clara preocupação ambientalista no sentido de denunciar a destruição da natureza e propor caminhos para sua preservação, apesar disso, a gritante importância da natureza não humana para a constituição do sujeitolírico feminino nos seus poemas não somente atende às preocupações de Buell como justifica um enfoque ecofeminista, cujas preocupações voltam-se não somente à denúncia da opressão masculina sobre o binômio natureza-mulher, como também à construção de novas 
subjetividades - não somente femininas - capazes de respeitar a natureza e as alteridades. Nela, não encontramos imagens de uma natureza domesticada, de jardineiro ou turista; o motivo do locus amoenus, tão comum na representação da natureza na literatura de tradição bucólica, seja clássica ou romântica, está praticamente ausente. Diversamente, ela é representada como exuberante e selvagem. No entanto, isto não a coloca em oposição ao humano, ou seja, como realidade ameaçadora que deve ser controlada ou mesmo destruída. Ao contrário, ela é vista como sagrada, pois genitora da vida em todas as suas formas. $\mathrm{O}$ eulírico feminino não apenas a valoriza, mas busca, principalmente, confundir-se com ela na tentativa de se conhecer e se elevar espiritualmente, de tal modo que a terra é representada como fêmea e a mulher como natureza de onde brota a vida, exuberante e incontrolável razão pela qual muitas vezes não sabemos ao certo se a voz que emerge dos poemas é a do eulírico feminino ou a da Natureza/Terra. Na verdade, é de ambas ao mesmo tempo, pois ser mulher e ser natureza se (con)fundem. E esta dimensão telúrica de sua poesia, em que o corpo feminino é marcado por signos da metamorfose e da fecundidade mesclados a outros que expressam sensualidade, dá forma a uma identidade feminina construída sob o arquétipo de Lilith e/ou Afrodite, os quais - especialmente o primeiro - representam a luta da mulher contra a sua sujeição pela sociedade patriarcal (PAIVA, 1990; CAVALCANTI, 1988, WHITMONT, 1991).

A visão sacralizadora da natureza e o desejo de nela se integrar como forma de harmonizar-se com o universo leva à valorização da filosofia zen-budista assim como da religiosidade afrobrasileira, sendo recorrente a atitude do eu-lírico feminino em se apresentar como filha de Ogum/São Jorge. A tensão entre estas duas religiosidades, tão diversas entre si, encontra um correlato objetivo na tensão entre a valorização do zen-budismo (mais visível nas fotos do que nos poemas), que propõe uma atitude contemplativa, e a torrencialidade da sua linguagem, expressiva de um Eros poderosíssimo que arrebenta dos poros em imagens por vezes grotescas. A parte esta tensão, o que se percebe é que a sacralização da natureza, concebida como genitora, volta-se para uma atitude de reencantamento da natureza, outro importante aspecto da política de algumas correntes ecofeministas, tais como a cultural e a socialista do chamado "Vento Sul".

Apesar das divisões teóricas internas ao movimento não determinarem fronteiras estanques e impermeáveis, o ecofeminismo cultural acredita em uma sensibilidade ecológica caracteristicamente feminina, pois considera que as mulheres possuem "uma relação superior com a natureza (...) biologicamente determinada, de forma que somente uma sociedade na 
qual as mulheres possam limitar ou controlar a influência dos homens poderá ser livre da agressividade e destruição do mundo natural” (DI CIOMMO, 1999, p. 155). Na tentativa de reverter o quadro social e histórico de opressão, este feminismo celebra "a fertilidade e a criatividade presentes no paganismo feminista, a religião que celebra a comunidade com a Terra como maternal e viva ou como a poderosa Deusa imanente no mundo" (DI CIOMMO, 1999, p. 156). De modo semelhante, o feminismo representado por Maria Mies e Vandana Shiva, embora tenha seu foco de preocupações voltado para as questões políticas envolvendo o Terceiro Mundo, também confere extrema importância às questões espirituais, religiosas e míticas presentes no debate. Ao tentar definir o escorregadio e ambíguo conceito de espiritualidade, ambas argumentam que a espiritualidade que interessa à política ecofeminista não é aquela que se encontra nas religiões monoteístas patriarcais - cristianismo, judaísmo e islamismo -, mas nos antigos cultos pagãos que, conforme demonstra Edward Whitmont (1982), foram (e ainda são) perseguidos ou desconsiderados por estas religiões que condenaram o politeísmo e o culto às deusas nas mais diversas culturas da Antiguidade. Para elas, a espiritualidade no ecofeminismo deve ser entendida como "o princípio feminino que reside em todas as coisas" (MIES; SHIVA, 1993, p. 28) “o princípio de ligação", a "energia vital (...) que dá às mulheres a capacidade de amar e de celebrar a vida. (...) espiritualidade sensual ou sexual, (...) amor sem o qual a vida não pode florescer" (MIES; SHIVA, 1993, p. 29). E esta visão sobre a espiritualidade encontra-se bem representada na poesia de Marcele Aires, o que pode ser percebido tanto na ausência do discurso e da simbologia cristãs, que são cambiados pela mitologia e pela religiosidade afro-brasileiras, como também na condenação ao pensamento racionalista cartesiano, uma vez que o eu-lírico feminino não se põe afoito "com o gozo racionalista" e nem carece de "epistemologias, / ciências ou matemáticas desbravando axiomas" (p. 118) que, para ele, não passam de "paredes de verdades" (p. 118), ou seja, de barreiras para o caminho do conhecimento, somente alcançável através da fé e da contemplação da natureza em uma atitude de reverência e celebração da dependência da Terra-Mãe que é "completamente oposta à atitude preconizada por Francis Bacon e pelos seus seguidores, os pais da ciência e da tecnologia modernas" (MIES; SHIVA, 1993, p. 29-30), pois consideravam a subordinação à natureza como um ultraje à liberdade. Na contramão deste pensamento, a poesia de Marcele Aires condena a ciência moderna como mais uma das estratégias de dominação da mulher e da natureza por parte do patriarcalismo vencedor.

Assim como as ecofeministas que se guiam pela valorização da espiritualidade, Marcele Aires se identifica com uma visão de mundo romântica na medida em que rejeita o 
racionalismo que promove a separação entre homem e natureza e, em contrapartida, promove o reencantamento do mundo através da magia, do misticismo, da sensualidade e do resgate de mitos capazes de constituírem e manterem vivas uma nova subjetividade, "un nuevo concepto de lo humano más abarcador, que integre sin rupturas todas sus dimensiones e incardine al ser humano en el mundo natural, (...), una nueva noción de existência humana arraigada em lo orgánico, absolutamente vinculada a lo vivo" (GUERRERO, 2010). Esta atitude do eu-lírico feminino em sua poesia é poeticamente confirmada pelo resgate do mito de Lilith, silenciado pela Igreja Católica e pelas diversas igrejas evangélicas, assim como pelas imagens do "antúrio nos cabelos" e dos "pés encardidos".

\section{Considerações finais}

Com base nas considerações feitas, é possível concluirmos que a poesia de Marcele Aires, embora não apresente uma preocupação ambiental explícita e nem realize uma crítica à dominação masculina, encontra-se imbuída de valores que a colocam em perfeita sintonia com os valores do ecofeminismo, especialmente de um ecofeminismo cultural, visto a forte relação entre natureza e espiritualidade segundo uma perspectiva romântica. Isto acontece na medida em que, opondo-se ao racionalismo científico cartesiano e positivista, que considera a dependência à natureza como aviltante à liberdade humana, sua poesia promove um reencantamento do mundo e da natureza na busca pela totalidade e reconhece uma sensibilidade ecológica feminina, assim identificando mulher e natureza e considerando ambas como sagradas em sua capacidade genitora. Tais posturas críticas que têm o mérito de reintroduzir "la dimensión natural en la definición de ser humano, con la pretensión de romper la dicotomia naturaleza/cultura (...) e instaurar una concepción de la existencia arraigada em la pluralidad ontológica" (GUERRERO, 2010) endossam o ponto de vista de Löwy e Sayre (1995, p. 255) quanto ao fato de que "o movimento ecológico constitui (...) a mais importante forma de renovação da crítica romântica contra a civilização industrial moderna". No entanto, algumas destas posturas são bastante passíveis de crítica, pois a atribuição de uma essência à natureza feminina assim como a sacralização da natureza apresentam limitações e perigos que podem enfraquecer a própria luta ecofeminista. Um dele é o irracionalismo que caracteriza certas posturas românticas. A crítica aos aspectos de dominação sobre o gênero feminino e o desrespeito à natureza que caracterizam a prática da ciência moderna são, sem dúvida, um importante avanço teórico no debate político, mas a generalização destas acusações a todo pensamento científico não somente é equivocada como 
também corre o risco de "jogar fora a criança juntamente com a água do banho", conforme reza o dito popular.

Com respeito à sacralização da natureza, Olaya Fernández Guerrero (2010), por exemplo, considera que "el mayor riesgo de esta propuesta es el de llevar a cabo una atribución de valores morales a un mundo natural que es completamente ajeno a la ética". Quanto ao essencialismo com respeito à natureza feminina, o perigo é ainda maior, pois ao defender uma diferença essencial entre o masculino e o feminino (atribuindo ao segundo características como intuição, sensibilidade, imaginação, identificação com a natureza e com o trabalho doméstico), a política ecofeminista corre o risco de recair nos estereótipos preconceituosos que tanto acusa, seja "invertendo os pratos da balança, ressaltando uma natureza feminina 'mais' positiva do que a masculina" (DI CIOMMO, 1999, p. 180), ou reafirmando os mesmos preconceitos que condenam as mulheres a uma posição inferior aos homens, historicamente identificados - do ponto de vista patriarcal e androcêntrico - com a cultura, a razão, o progresso e a civilização.

Por lo general, la palabra "ecofeminismo" evoca desconfianza y rechazo entre las feministas porque se la asocia con teorías que identificaban a las mujeres con el mundo natural. (...) El esencialismo de los textos "clásicos" ha sido presa fácil de la crítica no sólo por sus generalizaciones abusivas sobre las mujeres, sino por su peligro potencial de retorno a los estereotipos de la impotencia. La identificación de Mujer y Naturaleza, propia de numerosas culturas, forma parte de los discursos de legitimación patriarcal. Los significados y el bajo estatus conferidos a ambas a lo largo de la constitución de la racionalidad occidental prueban abundantemente esta función legitimadora del dominio (PULEO, 2008, p. 47).

A ausência do homem em sua poesia não permite concluirmos que ela considere a ligação com a natureza um privilégio feminino, ou melhor, das mulheres, pois a ausência do masculino não evidencia necessariamente uma repulsa ao homem e ao universo de valores masculinos, mas - antes de tudo - uma necessidade muito forte de autoafirmação de uma identidade feminina em oposição a uma cultura marcadamente patriarcalista e androcêntrica. A imagem que a autora faz dos homens e da masculinidade, portanto, é algo que por enquanto não podemos responder. Por conseguinte, uma atenção às relações entre mulher e homem, entre feminino e masculino, é algo que só poderá enriquecer a sua poesia se, futuramente, for acrescentada aos temas tratados por ela.

\section{Referências}

CAVALCANTI, R., O casamento do sol com a lua: uma visão simbólica do masculino com o feminino. São Paulo: Cultrix, 1988. 
DI CIOMMO, R. C., Ecofeminismo e educação ambiental. São Paulo: Editora UNIUBE/Editora Cone Sul, 1999.

FRANCESCHINI, M. A., Que transpõe o halo. (Trilogia poética). Cambé/PR: Wgraf, 2010.

GARCIA, L. Ecofeminismo: múltiplas versões. In: Revista Ártemis. Vol. 10, Jun. 2009, p. 96118. Disponível:

<http://periodicos.ufpb.br/ojs/index.php/artemis/article/view/11829> . Acesso: 17/5/2013.

GARRARD, G., Ecocrítica. Trad. De Vera Ribeiro. Brasília: Editora da UnB, 2006.

GONZÁLEZ, M. O., Globalización, ecologia y literatura. In: Kipus. Revista Andina de Letras. $\quad$ N. 27, p. 97-109, $1^{\text {o }}$ semestre, $2010 . \quad$ Disponível: $<$ http://repositorio.uasb.edu.ec/bitstream/10644/2282/1/07-CR-Ostria.pdf $>$. Acesso: $17 / 5 / 2013$.

GUERRERO, O. F., Cuerpo, espacio y libertad en el ecofeminismo. Nómadas. Revista Crítica de Ciencias Sociales y Jurídicas. Vol. 27, n. 3, 2010. Disponível: <http://www.ucm.es/info/nomadas/27/olayafguerrero.pdf>. Acesso: 17/5/2013.

LEMINSKI, P., Vida: Cruz e Sousa, Bashô, Jesus, Trotski. Porto Alegre, Sulina, 1990.

LÖWY, M.; SAYRE, R., Revolta e melancolia. O romantismo na contramão da modernidade. Tradução de Guilherme João de Freitas Teixeira. Petrópolis/RJ: Vozes, 1995.

MIES, M.; SHIVA, V., Ecofeminismo. Lisboa: Instituto Piaget, 1993.

ODUM, E. P.; BARRET, G. W., Fundamentos de Ecologia. Tradução de Pégasus Sistemas e Soluções. Revisão Técnica de Gisela Yuka Shimizu. Lisboa: Fundação Calouste Gulbenkian, 2001 .

PAIVA, V., Evas, Marias, Liliths... as voltas do feminino. São Paulo: Brasiliense, 1990.

PULEO, A., H. Libertad, igualdad, sostenibilidad. Por un ecofeminismo ilustrado. Isegoría. Revista de Filosofía Moral y Política. N. 38, Enero-Junio, p. 39-59, 2008 . Disponível: $<$ http://isegoria.revistas.csic.es/index.php/isegoria/article/download/402/403>. Acesso: $17 / 5 / 2013$.

WHITMONT, E. C., Retorno da Deusa. Tradução de Maria Sílvia Mourão. São Paulo: Summus Editorial, 1991.

Crédito das imagens

DIEZ, G., Butaneses em imagens. In: Revista JIOP. Maringá: Editora do Departamento de Letras. Maringá: UEM, n. 2, p. 422-426, 2011. Disponível: $<$ http://www.dle.uem.br/revista_jiop_1/revista_jiop_2.pdf $>$. Acesso: 17/5/2013.

[Recebido em maio de 2013 e aceito para publicação em outubro de 2013] 
The importance of nature to the construction of a feminine identity in the poem Que transpõe o halo, by Marcele Aires: an analysis by the prospect of ecofeminismo

Abstract: Nature representations vary according to different speeches and artistic forms. Throughout Literature history, they have been predominantly oriented by diverse interests, such as scientific, commercial, political, as well as expressive. From one pole to other, its representation has served to disclose its wealth (as happened to travel literature in colonial period), to consolidate a national and/or regional identity (what happens to romanticism and modernism literatures, as well as to regionalism), to confirm theses on biological determinism on human behavior (what happens to realism/naturalism literature), or to express subjectivity of the characters themselves or of lyrical subjects (what happens especially to romanticsymbolist literature), being led, in each case, by different world visions. Recently, accompanying the emergence of an ecological awareness that is opposed to ideologies that consider it just as a natural resource to be explored, nature has been appreciated per si, what does not exclude its relation to subjectivity which represents it and to which is important. To discuss this issue according to the critic ecofeminism point of view, we analyze the poems of the book Que transpõe o halo in order to show the importance of nature in constructing a feminine identity in the mentioned book.

Keywords: Ecocriticism. Ecofeminism. Women's writing. Literature from Paraná. Nature and subjectivity. Poetry from Paraná.

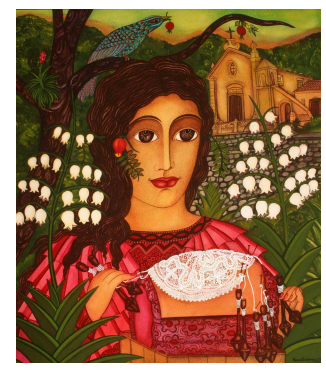

